\title{
Developing a hospital preparedness checklist to assess the ability to respond to the COVID-19 pandemic
}

\author{
Hesam Seyedin, ${ }^{1,2}$ Shandiz Moslehi, ${ }^{1,2}$ Fazeleh Sakhaei ${ }^{1,2}$ and Mohsen Dowlati ${ }^{1,2}$
}

${ }^{1}$ Health Management and Economics Research Center, Iran University of Medical Sciences, Tehran, Islamic Republic of Iran. ${ }^{2}$ Department of Health in Disasters and Emergencies, School of Health Management and Information Sciences, Iran University of Medical Sciences, Tehran, Islamic Republic of Iran. (Correspondence to: Mohsen Dowlati: dowlati.m@iums.ac.ir).

\begin{abstract}
Background: During epidemics and pandemics, health systems, and especially hospitals, face many challenges in the management of patients and staff. Hospital preparedness measures are critical for hospitals to respond effectively to the admission and management of COVID-19 patients. Ministry of health policy for pandemics must cover the ability of hospitals to respond to COVID-19.

Aims: The aim of this study was to develop a checklist for evaluating the preparedness of hospitals to respond to the COVID-19 pandemic.

Methods: We searched for and reviewed available evidence, including the literature and guidelines presented by related organizations. Due to the COVID-19 outbreak, face-to-face interview was not possible so we used telephone and video connections, mobile applications and email for unstructured interviews. Checklist development was carried out by a multidisciplinary panel of experts.

Results: After applying the opinions of the experts, the final checklist had 2 main domains: measures at national and measures at hospital level. Preparedness at national level was categorized into 3 aspects that are implemented by the health ministry. Preparedness at hospital level was categorized in 24 subgroups.

Conclusion: Hospital preparedness for admission and management of COVID-19 patients is essential. A checklist for the assessment of hospital preparedness for COVID-19 patient management and hospital management was designed and developed. Our preparedness assessment checklist is an expanded tool that provides clear and practical guidance that can be adapted for any hospital admitting COVID-19 patients.

Keywords: hospital preparedness, checklist, epidemic, pandemic, COVID-19

Citation: Seyedin H; Moslehi S; Sakhaei F; Dowlati M. Developing a hospital preparedness checklist to assess the ability to respond to the COVID-19 pandemic. East Mediterr Health J. 2021(2):131-141 https://doi.org/10.26719/2021.27.2.131

Received: 08/06/20; accepted: 19/10/20

Copyright @ C World Health Organization (WHO) 2021. Open Access. Some rights reserved. This work is available under the CC BY-NC-SA 3.0 IGO license (https://creativecommons.org/licenses/by-nc-sa/3.0/igo)
\end{abstract}

\section{Introduction}

Novel Coronavirus disease 2019 (COVID-19) is a potentially severe acute respiratory infection. The COVID-19 outbreak began in December 2019 in Wuhan City, Hubei Province, China (1). The COVID-19 pandemic has become a global health concern since it infects people worldwide (2). It spreads quickly, and many countries have now reported laboratory-confirmed cases. The World Health Organization (WHO) has confirmed 16495309 cases and 654327 deaths have been detected globally (28 July 2020). During disease outbreaks, health systems, especially hospitals, may face many challenges, including shortages of hospital personnel, medical supplies and support services, which all make it difficult for managers to effectively manage hospital overcrowding. Hospital preparedness activities are an essential component of hospital disaster preparedness for mass casualty incidents and need to address all hazards, including infectious disease outbreaks and pandemics (3). Due to the main role of hospital preparedness, especially, in response to outbreaks, it is important to focus on hospital and personnel preparation. Recently, looking at the situation of hospitals in the face of the COVID-19 pandemic (4-6), and based on studies that have been carried out, it is clear that most hospitals across the world are not prepared for the biological emergency and may inappropriately respond to disease outbreaks, particularly in their capacity to care for large numbers of patients $(7,8)$.

Standard operating procedures and guidelines are necessary to remind clinicians of the need for medical evaluations and to incorporate certain aspects of treatment (9). Governance, especially from the health ministry, plays an important role in hospital management through external collaboration, government policies, the national health care system and government financial incentives (10).

The COVID-19 epidemic is unique because of its extensive scale, the high rate at which it spread globally, the lack of pre-existing scientific information and the importance of media coverage (10). It forced hospitals to face significant new challenges associated with this epidemic (11). Hospitals will face an increasing number of COVID-19 patients and have to forecast the consequences, 
including the need for an increase in the number of beds, trained health care workers and ventilators (12).

Specific hospitals should be prepared for the admission of COVID-19 patients, and these hospitals should ensure their staff are trained and equipped with personal protective equipment (PPE). The spread of COVID-19 within the health care facility should be prevented; patients with possible COVID-19 should be identified; care for a limited number of patients with confirmed or suspected COVID-19 should be performed routinely; all health care personnel should be monitored and managed due to the possibility of exposure to COVID-19; and effective communication within the facility should be conducted. Planning for proper external communication related to COVID-19 should also be incorporated (13).

Hospitals should be evaluated regarding their preparation for the pandemic and for admitting patients. This requires the proper tools for evaluation of preparedness functions and subsequently resolving weakness and improvement of strengths. Therefore, the aim of this study was to develop a checklist for the evaluation of hospital preparedness for COVID-19. Our checklist will assess the status of hospitals and can be used by hospital managers, directors and authorities and the health system. The output and results of this report may help to promote hospital preparedness for an appropriate response to the COVID-19 pandemic.

\section{Methods}

\section{Review of literature and guidelines}

To determine the nature and format of the core information to be contained in a hospital preparedness checklist for COVID-19 patients, we searched for and reviewed available evidence, including the literature and guidelines presented by related organizations. We searched Web of Science, PubMed and Google Scholar for relevant articles from January 2019 to April 2020. We also searched specialized databases and websites such as the Federal Emergency Management Agency (FEMA), the WHO, the Pan American Health Organization (PAHO) and the Centers for Disease Control and Prevention (CDC). Combinations of the following Medical Subject Headings (MeSH) key words were used: "COVID-19", "hospital", "emergency room", "preparedness", "preparation", "management", "response", "epidemic", "pandemic", "outbreak", "infectious disease" and "biological event". Then the bibliographies of all relevant articles were reviewed to identify additional studies. We conducted a focused study of selected available resources (Open Research Dataset, Biorxiv and Medrxiv, PubMed - LitCovid, Cochrane Library, GIDEON, CDC and Jove) related to COVID-19 that had been published after 2019 .

\section{Consultation with experts by interview}

This study was conducted from 10 January to 18 July 2020. Due to the restrictions implemented during the COVID-19 outbreak, face-to-face interviews were not possible and we used telephone and video connections, mobile applications and email for unstructured interviews. Participants included experts from multiple disciplines, including hospitalists, hospital administrators, hospital managers, disaster committee managers, matrons, nurses, researchers, emergency physicians, infection physicians, academics, and hospital administrators who had had direct experience in hospital management and infectious diseases. The composition of the panel is shown in Table 1.

The main focus of the topics discussed included effective measures for hospital management in the COVID-19 outbreak and the strengths and weaknesses of the hospital in the face of the outbreak. The draft checklist was then shared with the panel members to seek their input.

This checklist has been developed to improve hospital management during the COVID-19 outbreak. The elements described in the list may not be applicable to all hospitals and may need to be adapted to the specific characteristics of the hospital, the individual national health system, and the legislation and community norms where the hospital is located.

\section{Checklist development}

The results of the literature review were further supplemented with expert opinion and practical advice. As a first step, the panel of experts reviewed existing toolkits and evidence-based recommendations around best hospital preparedness practices (details of the make-up of the expert panel are shown in Table 1). During meetings via video connection or mobile applications, panel members were assigned to 3 groups and instructed to review summarized toolkits and literature using context-specific aspects (infection control, patient management, surge capacity) (Figure 1). Following the meeting, each group was tasked to generate a list of evidence-based items necessary for COVID-19 hospital preparedness within the context of the group's assigned aspect. Every subgroup reached consensus on items specific to its context. An initial draft checklist was generated based on input from all subgroups. The checklist was created using recommended PAHO, WHO and CDC concepts. The next meeting provided the opportunity for individual comments and feedback on the initial draft checklist. Three cycles of checklist revision were conducted followed by comments and feedback through exchanges via email and mobile applications. A final meeting resulted in consensus of the expert panel on every element of the hospital preparedness for COVID-19 checklist. During this final meeting, approval of the checklist was completed.

\section{Ethical approval}

This study was completed in accordance with the ethical principles of, and was approved by, the research ethics committee of Iran University of Medical Sciences, Tehran (IR.IUMS.REC.1397.1379). 


\begin{tabular}{|c|c|c|}
\hline Affiliation & Academic degree & Technical expertise \\
\hline Head of disaster risk reduction department & MD-MPH & Physician \\
\hline Hospital laboratory expert (2 people) & MSc, $\mathrm{PhD}$ & Laboratory science \\
\hline Head of environmental health department of hospital (2 people) & MSc & Environmental health \\
\hline Pre-hospital centre management & MSc & Nursing \\
\hline Head nurse of emergency department & MSc & Nursing \\
\hline Medical education deputy in medical university & $\mathrm{PhD}$ & Medical education \\
\hline Head of emergency department & Medical specialty & Emergency medicine \\
\hline Head of centre for disease control and prevention & MD-MPH & Physician \\
\hline Head of infectious diseases department ( 2 people) & Medical specialty & Infectious diseases \\
\hline Head of virology department ( 2 people) & $\mathrm{PhD}$ & Virology \\
\hline Head of passive defence committee & MD-MPH & Physician \\
\hline Head of drug hospital store & $\mathrm{PhD}$ & Clinical pharmacy \\
\hline Head of environmental health and safety department of hospital & MSc & Environmental health \\
\hline Head of hospital (2 people) & Medical specialty & Emergency medicine \\
\hline Hospital director & MD-MPH & Physician \\
\hline Health sector of military system & $\mathrm{PhD}$ & Biological defence \\
\hline Passive defence deputy of university of medical sciences & $\mathrm{PhD}$ & Environmental health \\
\hline Treatment deputy of hospital & MD-PhD & Health in disasters \\
\hline Treatment deputy of university of medical sciences & Medical specialty & Emergency medicine \\
\hline Head of hospital nursing office (matron) (2 people) & $\mathrm{PhD}$ & Nursing \\
\hline Education deputy of hospital & Fellowship & Clinical toxicology \\
\hline National centre for disease control and prevention ( 2 people) & Medical specialty, MD-MPH & Infectious diseases \\
\hline Head of hospital occupational medicine department & Medical specialty & Occupational medicine \\
\hline Head of university medical emergencies management centre & $\mathrm{MD}, \mathrm{PhD}$ & health in disasters \\
\hline Head of emergency operation centre & MSc & Health care management \\
\hline Hospital supervisor (2 people) & MSc & Nursing \\
\hline Bacteriology laboratory expert & $\mathrm{PhD}$ & Medical bacteriology \\
\hline Head of hospital disaster management committee & MSc & Occupational health \\
\hline Supervisor of hospital infection control committee & $\mathrm{PhD}$ & Nursing \\
\hline Head of reference laboratory & $\mathrm{PhD}$ & Medical biotechnology \\
\hline Hospital research centre & MSc & Epidemiology \\
\hline Head of pulmonary diseases department & Medical specialty & Pulmonary diseases \\
\hline
\end{tabular}

\section{Results}

After applying the opinions of the experts, the final checklist had 2 main domains: measures at national level and measures at hospital level. Preparedness at national level was categorized into 3 aspects: coordination, referrals hospitals and legal subgroups; these measures are performed by the ministry of health. Preparedness at the hospital level was categorized in subgroups: planning, surveillance system, prioritization and triage, external cooperation and interaction of hospitals, hospital incident command system, surge capacity, COVID-19 patient management, non-COVID-19 patient management, intensive care unit, drug and medical equipment management, management of volunteers, management of companions of patients, hospital personnel management, security, nutrition and food health, research and documentation, communications, quarantine, exercises and training, laboratory, PPE, environmental health, hospital infection prevention and control, and dead body management. Each subgroup encompasses related indicators and is classified according to whether it is "Completed", "In progress" or "Not started" (Table 2). Items classed as in progress will be followed up for completion. Then, attempts will be made to initiate those items that have not been started.

Because of variability between outbreaks and the characteristics of individual hospitals (such as patient population, size of hospital/community and scope of service), each hospital will need to adapt this checklist to meet its unique needs and situation.

\section{Discussion}

Hospital preparedness for disasters such as epidemics is critical. This checklist was designed to prepare hospitals 


\begin{tabular}{|c|}
\hline Review of literature and guidelines \\
\hline Consultation with panel experts by interview \\
\hline Surge capacity Infection control Patient management \\
\hline Groups generated lists of items necessary for hospital preparedness \\
\hline \\
\hline Revised draft checklist circulated for comments and feedback \\
\hline
\end{tabular}

for effective management of COVID-19 patients; it was designed and developed at a time when all countries already had many COVID-19 patients and hospitals were dealing with them. Nevertheless, the checklist is extremely useful: it and can help hospitals to best assess their situation and make necessary improvements for COVID-19 management. We used a consensus process among stakeholders to develop the checklist for the assessment of hospital preparedness for COVID-19 that needs to be completed for every hospital admitting COVID-19 patients. The hospital response to epidemic and pandemic situations (with high numbers of patients and visits) demands a proper evaluation tool. We believe that preparedness planning starts before the event. The components of the assessment checklist should include all aspects of hospital management to ensure proper response and care of patients.

Some tools and checklists have been developed for hospital assessment by PAHO (14), CDC (15), and the European Centre for Disease Prevention and Control (ECDC) (16). One study was conducted with the aim of developing an assessment tool for the evaluation of hospital preparedness in chemical, biological, radiological and nuclear emergencies through the cross-sectional Delphi technique (17). Assessment items were categorized into 7 sections: planning and organization, safety and security, standard operation process, communication, resources, medical management and decontamination. In comparison, our checklist focused on the biological event and COVID-19 disease. In 2004, Hopkins et al. developed a SARS preparedness checklist for state and local health officials covering 6 issues: legal authority and policy issues, surge capacity, communication, laboratory, surveillance, and preparedness in other agencies (18). Another report was published by Adini et al. in 2014 on the development of an evaluation tool for assessing the preparedness of medical facilities for epidemics and pandemics. Five categories (evaluation dimensions) were described: policy and planning, medical management, personnel, communication and infrastructure (19).

We categorized measures based on the tasks of the ministry of health at the national level and on hospital activities. Our expert panel was multidisciplinary and had broad representation from physicians, managers, policy-makers and nurses, incorporating all possible aspects of hospital preparedness (Table 1). Our tool extends beyond a checklist of tasks to be conducted: rather it serves as a platform and model to facilitate interprofessional collaboration through joint meetings with the participation and collaboration of various experts. In addition, our tool follows an explicit and defined consensus process. Finally, our proposed checklist better follows a recommended checklist format. It prompts hospital providers to perform the steps necessary for successful COVID-19 patient management while allowing for other hospital services and other (non-COVID-19) inpatients to continue. We suggest using the checklist during the first and recovery phases and before facing a large number of patients to ensure proper management of suspected and confirmed patients.

Several limitations of this study should be considered. First, the current literature on COVID-19 is limited. Second, the checklist has not yet been tested. The next step of this research is to assess the checklist in a pilot study. We plan to collect baseline, process and outcome measures before and after the implementation of the checklist in a hospital.

\section{Conclusion}

Standardization of preparedness measures is critical to the response of hospitals regarding the admission and management of COVID-19 patients. Our preparedness assessment checklist is an expanded tool that provides clear 


\section{Table 2 Hospital preparedness assessment checklist for COVID-19}

National level

\section{Coordination}

Using the experiences of other countries

Coordinate with insurance organizations to provide services to COVID-19 patients Provide legal mechanisms for the use of volunteers and insurance of volunteers

Establishment of a network for the supply and management of drugs and medical equipment between hospitals

\section{Referrals hospitals}

Hospital rankings for providing services to COVID-19 patients: identify specific hospitals for infectious patients

Appointment of referral hospitals for admission of COVID-19 patients

Definition of reference system for COVID-19 patients to hospitals

Equipping referrals hospitals with diagnostic and treatment facilities such as laboratory, radiology

\section{Legal}

Supplementary insurance of staff for treatment of COVID-19

Insurance of hospital equipment and facilities

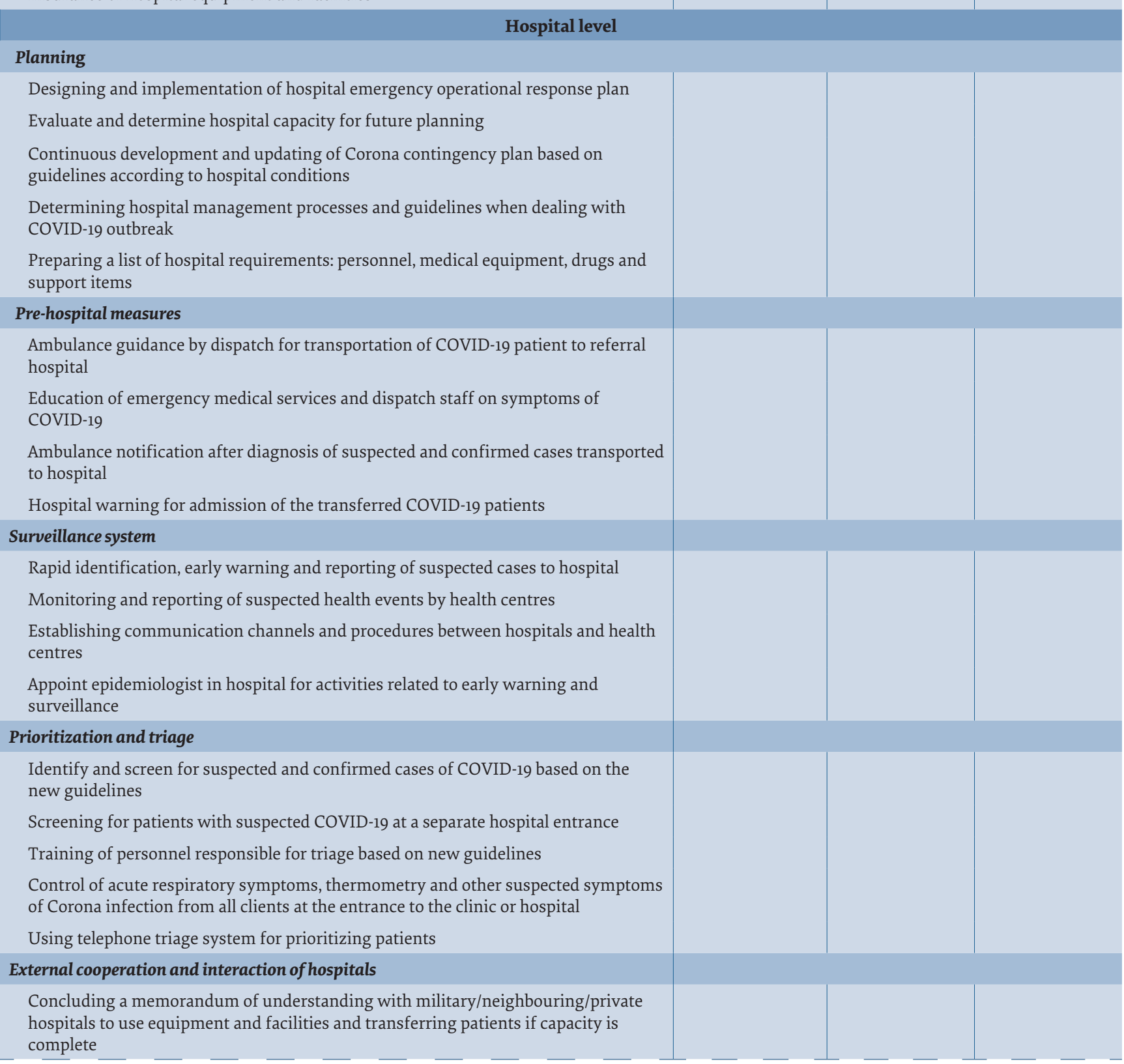




\section{Table 2 Hospital preparedness assessment checklist for COVID-19 (continued)}

Measure

Preparation of coordination process with reference laboratories

Preparation of coordination process with health centres

Establish a channel of communication with hospitals involved with COVID-19 through video conferencing

\section{Hospital incident command system}

Development of hospital command centre into a secure and well-equipped place

Holding continuous meetings of members of the command team in hospital command centre

Appoint a specialist consultant in the system (infectious disease specialist, virologist, epidemiologist)

Presence of other related organizations in the hospital command centre

Communicate job descriptions to employees based on existing framework

Continuous monitoring of the hospital situation and communication with the emergency operations centre

Appoint a public officer to interact with the media as a spokesperson

Determining the liaison officer and coordinating to communicate with out-ofhospital organizations

\section{Surge capacity (physical space, staff, supplies and processes)}

Field hospital set up in the yard or environs of the hospital for COVID-19 patients Set up a special emergency support unit for COVID-19 patients

Clearance of elective patients in need of elective services

Increase the number of special care and radiology beds as much as possible

Rapid transfer of patients from the emergency room to other wards or hospitals Preparing and allocating other hospital wards to COVID-19 patients

Adequate storage of water and food in the hospital based on the number of beds and staff

Provide vital hospital equipment, including oxygen, water, electricity, food, Internet, telephone

\section{COVID-19 patient management}

Provide patient care following national and international guidelines

Presence of counsellor and psychologist to strengthen morale of COVID-19 patients

Provide continuous monitoring of vital signs (e.g. temperature, blood pressure, pulse, respiratory rate, level of consciousness, clinical signs of dehydration, shock) and oxygen saturation (pulse oximetry or blood gas analyses)

Treatment and care of mild cases at home remotely

Decontamination of COVID-19 patients' secretions

Appropriate coverage of hospitalized COVID-19 patients to prevent transmission of infection

Use of disposable personal items for COVID-19 patients such as sheets, pillows,

glasses, food containers

Perform medical interventions with safety precautions

Perform final tests to ensure complete recovery

Self-care training and patient follow-up after discharge from the hospital

Determining the person responsible for answering the questions and concerns of the patient's companions

Ability to communicate remotely with COVID-19 inpatients from the hospital

\section{Non-COVID-19 patient management}

Provide care and treatment services to other hospitalized patients

Special facilities for vulnerable groups such as pregnant mothers and children and people with chronic diseases (haemodialysis and infusion services, chemotherapy)

Complete separation of COVID-19 department

Meeting restrictions on non-COVID-19 patients 


\section{Table 2 Hospital preparedness assessment checklist for COVID-19 (continued)}

\section{Intensive care unit (ICU)}

Continuous replacement and updating of equipment in ICU

Ventilation system optimization based on standards of infectious patients' admission Availability of decontamination facilities for personnel

Restrictions on movement in ICU

\section{Drug and medical equipment management}

Provide appropriate funding for the provision of drugs and medical equipment needed by COVID-19 patients

Memorandum of understanding with pharmaceutical and medical equipment companies

Controlling the quantities and expiration date of drugs and medical equipment consistently

Continuous monitoring of drug reserves and medical equipment consumed and residual items

Proper stockpiling and safe storage of drugs and medical equipment

Management of volunteers

Identify and use the capacity of volunteers and charities

Organize volunteers and prevent hospital disruption

Prevent the involvement of charities and volunteers in specialized activities

Identifying and concluding a memorandum of understanding with associations and nongovernmental organizations

Observance of safety protocols for employing non-specialist forces in the hospital

Complete training of volunteer forces before starting work

\section{Hospital personnel management}

Practical measures for stress management of staff to reduce panic

Supporting the families of hospital staff

Supply of additional expert staff from outside the hospital (other hospitals, volunteers, retired staff)

Reduce hospital administrative staff as much as possible when dealing with COVID-19

Use the capacity of medical science students if needed

Do not use personnel with chronic diseases

Use occupational health mechanisms that ensure the well-being and safety of personnel during the response, including monitoring of exposed personnel Allocation of special benefits and privileges of personnel involved with COVID-19 Treatment and care of staff with COVID-19 by the hospital until complete recovery Assign shifts and rest periods to personnel for recovery

Determining a suitable place for the recovery of staff (hotel, guest house, etc.) if it is not possible to return home

Providing psychosocial support services for the families of staff and patients

\section{Security}

Securing hospital staff and facilities

Protecting patients' confidential documents and information

Provide security for hospitalized patients

Management of crowds and gatherings around the hospital

\section{Nutrition and food health}

Distribution of food in disposable containers

Determining the person in charge of food distribution for COVID-19 patients

Use the appropriate diet for COVID-19 patients

Supervision of hospital kitchen hygiene

Disinfection of food distribution equipment 


\section{Table 2 Hospital preparedness assessment checklist for COVID-19 (continued)}

$\begin{array}{llll}\text { Measure } & \text { Completed } & \text { In Progress Not Started } \\ \text { Research and documentation } & & \text { N }\end{array}$

\section{and documentation}

Cooperation of the hospital to carry out research projects on COVID-19

Hospital cooperation/consultation with basic science groups in medical universities, such as virology, health care management, health in disaster, epidemiology

Collaborate in the implementation of clinical trial test research

Documentation and registration of lessons learnt from exercises and exercise documentation to provide corrective programmes

\section{Communication}

Prevent rumours from the hospital

Reassuring people to go to hospital if they have acute symptoms

Define a dedicated COVID-19 code to alert the hospital

\section{Quarantine}

Establishment of places around the hospital to quarantine patients

Coordinate with the established facilities of other institutions and organizations for quarantine

Identify the proper place for quarantine such as a hotel, stadium, mosque, hall

Plan to create an area to separate patients with respiratory symptoms

\section{Exercises and education}

Training of all department and staff in hospital on COVID-19

Performing exercise with other organization involved to COVID-19 patients management

Specific training of COVID-19 department staff (vitalizing measures, communication skill, soothing skills)

Training of family staff about home quarantine and self-care

Education and responding to people's questions through telephone and online systems

Using telemedicine, media and cyberspace for education and sharing information

Develop a comprehensive programme for continuous training of hospital staff

Training of sampling methods and transportation of COVID-19 samples

\section{Laboratory}

Warning to laboratory before sending suspected COVID-19 specimens

Non-involvement of the main laboratory of the hospital with COVID-19 samples

Proper and safe transfer of suspected samples from the hospital to the laboratory following biosafety measures

Training of biosafety and biosecurity principles for laboratory personnel Appoint a safety officer in each laboratory

Continuous availability of basic laboratory testing (e.g. complete blood count, biochemistry profile, electrolytes, blood gas analysis, blood culture, sputum examination).

\section{Personal protective equipment (PPE)}

Provide quality and quantity of PPE (medical/surgical masks, N95/FFP2 respirators, gloves, gowns, eye protection)

Assistant present when donning PPE

Physical health of individuals to use PPE

Funding for the provision and maintenance of PPE

Control and testing of PPE before use

Provide quality PPE in various sizes

\section{Environmental health}

Frequent control of hospital water quality

Correct and regular chlorination of the hospital water tank

Treatment of infectious hospital waste water

Medical and infectious waste management

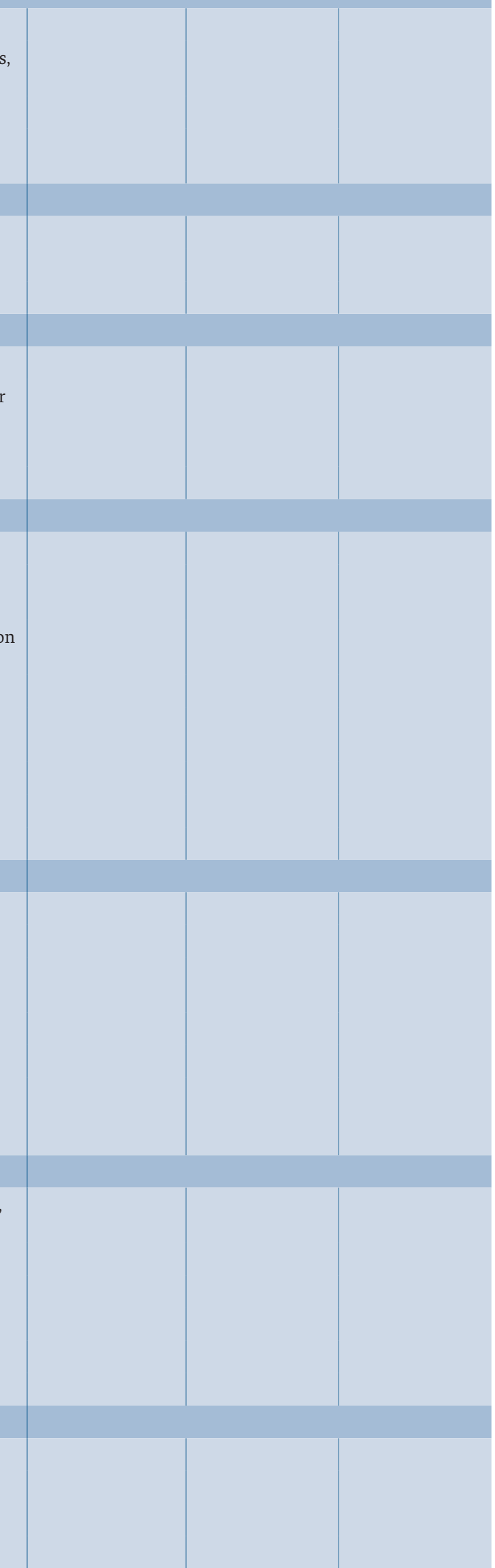




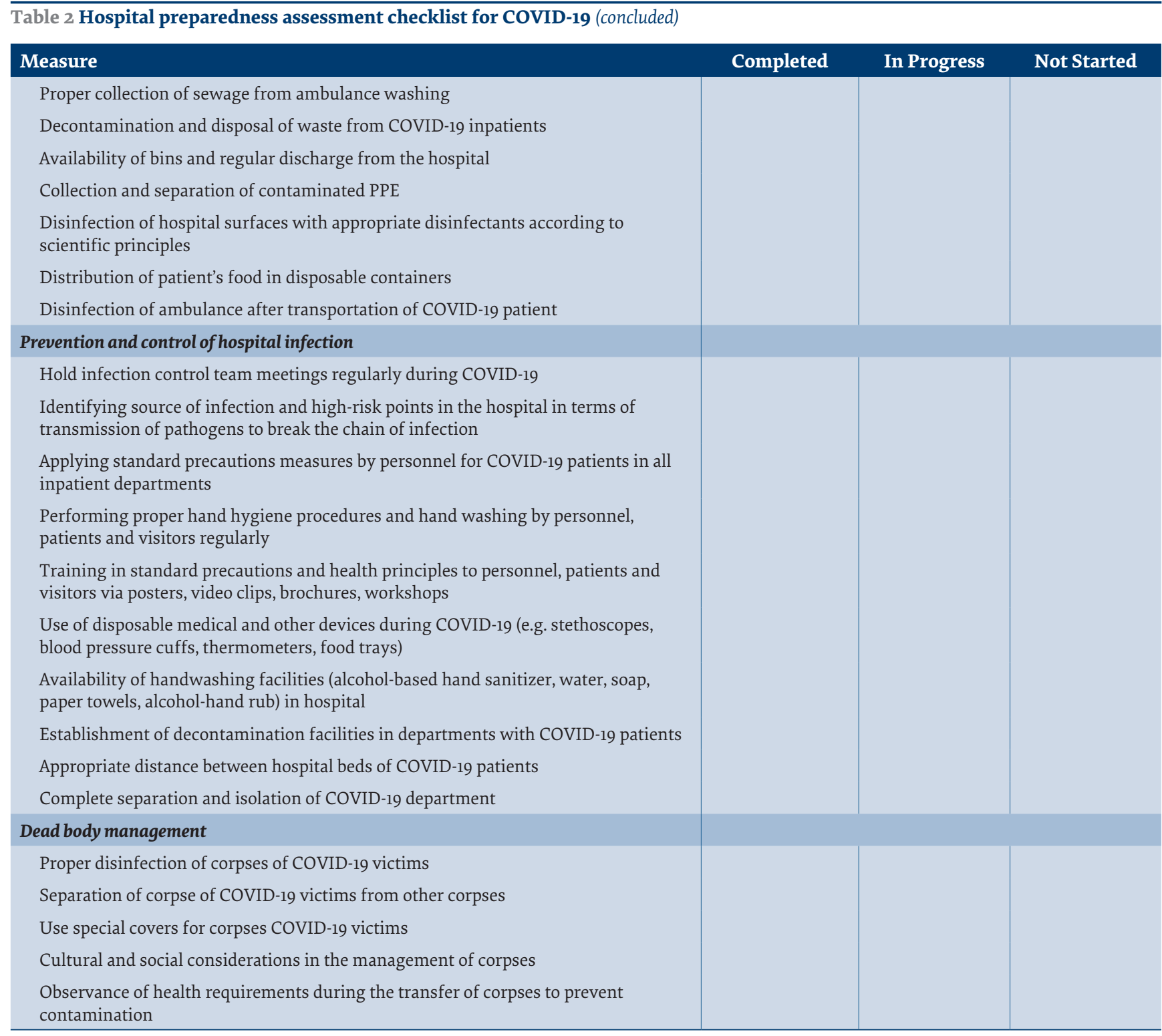

and practical guidance for each hospital, it can be adapted for any hospital admitting COVID-19 patients and will aid interdisciplinary efforts towards successful hospital management. We suggest future studies be carried out to assess hospital preparedness using this the checklist to improve the strengths and minimize the weaknesses of the hospital.

Funding: None.

Competing interests: None declared.

\section{Établissement d'une liste de contrôle sur la préparation des hôpitaux pour évaluer leur capacité à riposter à la pandémie de COVID-19}

\section{Résumé}

Contexte : Pendant une épidémie ou une pandémie, les systèmes de santé, et en particulier les hôpitaux, font face à de nombreuses difficultés dans la prise en charge des patients et la gestion du personnel. Les mesures de préparation des hôpitaux sont essentielles pour leur permettre de réagir efficacement à l'admission et à la prise en charge des patients atteints de COVID-19. La politique du ministère de la santé en matière de pandémies doit couvrir la capacité des hôpitaux à riposter face à la COVID-19.

Objectifs : Le but de la présente étude était d'élaborer une liste de contrôle pour évaluer l'état de préparation des hôpitaux en vue de riposter à la pandémie de COVID-19.

Méthodes : Nous avons recherché et examiné les données disponibles, y compris la littérature et les lignes directrices présentées par les organisations concernées. En raison de l'épidémie de COVID-19, les entretiens en présentiel n'ont pas 
été possibles; nous avons donc eu recours à des connexions téléphoniques et vidéo, des applications mobiles et au courrier électronique afin de mener des entretiens non structurés. L'établissement de la liste de contrôle a été réalisé par un groupe d'experts multidisciplinaire.

Résultats : Après avoir appliqué les avis des experts, la liste de contrôle finale comportait deux domaines principaux : des mesures au niveau national et hospitalier. La préparation au niveau national a été classée en trois aspects qui sont mis en œuvre par le ministère de la santé. La préparation au niveau hospitalier a été répartie en 24 sous-groupes.

Conclusion : La préparation des hôpitaux à l'admission et la prise en charge des patients atteints de COVID-19 est essentielle. Une liste de contrôle pour l'évaluation de la préparation des hôpitaux à la prise en charge de ces patients et la gestion hospitalière a été mise au point et appliquée. Notre liste de contrôle pour l'évaluation de la préparation est un outil élargi qui fournit des indications claires et pratiques pouvant être adaptées à tout hôpital qui admet des patients atteints de COVID-19.

$$
\begin{aligned}
& \text { إعداد قائمة مرجعية لتأهب المستشفى لتقييم قدرثه على الاستجابة لجائحة كوفيد-19 } \\
& \text { حسام سيدين، شانديز مصلحى، فاضله سخائى، محسن دولتى } \\
& \text { الخلاصة }
\end{aligned}
$$

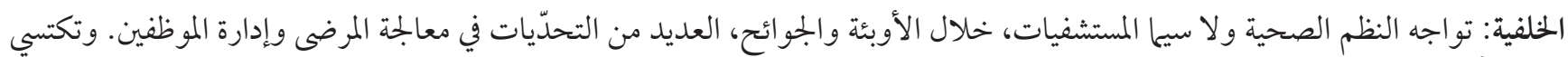

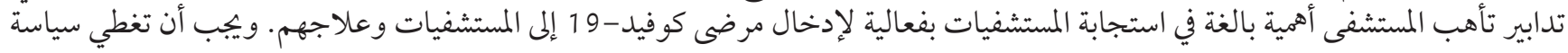

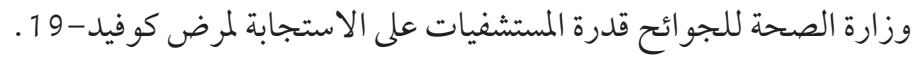

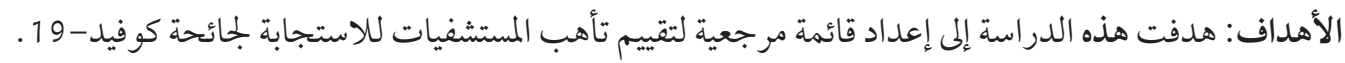

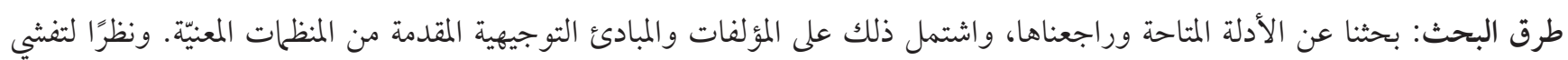

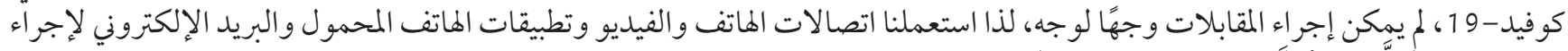

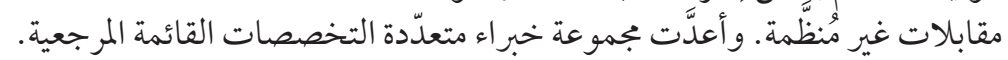

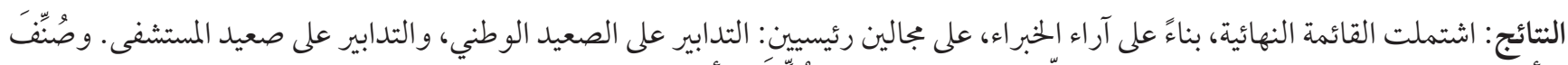

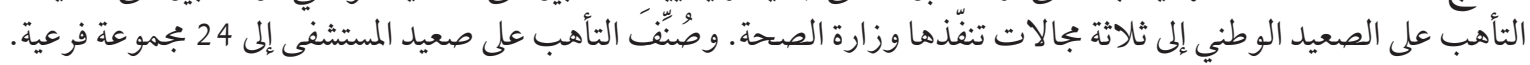

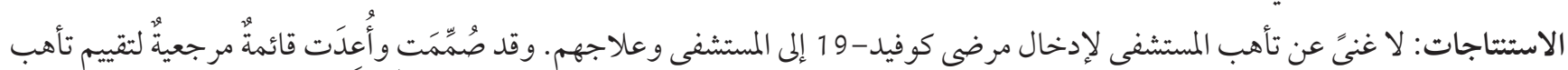

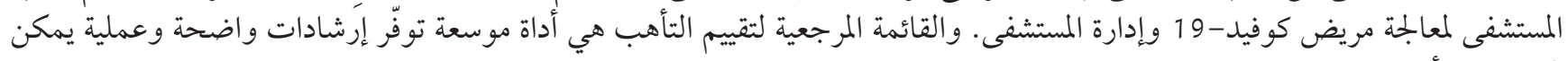
تكييفها مع أي مستشفى يقبل مرضى كوفيد-19 موفي 19.

\section{References}

1. Ren L-L, Wang Y-M, Wu Z-Q, Xiang Z-C, Guo L, Xu T, et al. Identification of a novel coronavirus causing severe pneumonia in human: a descriptive study. Chin Med J (Engl). 2020;133(9):1015-24. doi:10.97/CM9.0000000000000722

2. Statement on the second meeting of the International Health Regulations (2005) Emergency Committee regarding the outbreak of novel coronavirus (2019-nCoV). Geneva: World health Organization; 2020.

3. Rebmann T. Assessing hospital emergency management plans: a guide for infection preventionists. Am J Infect Control. 2009 Nov;(9):708-14. e4. doi:10.1016/j.ajic.2009.04.286.

4. Chopra V, Toner E, Waldhorn R, Washer L. How should U.S. hospitals prepare for coronavirus disease 2019 (COVID-19)? Ann Intern Med . 2020 May 5 2020;172(9):621-2.

5. Dunlop A, Lokuge B, Masters D, Sequeira M, Saul P, Dunlop G, et al. Challenges in maintaining treatment services for people who use drugs during the COVID-19 pandemic. Harm Reduct J. 2020 May 6;17(1):26. doi:10.1186/s12954-020-00370-7

6. Mohammad E, Reza N, Razieh F. COVID-19 epidemic: hospital-level response. Nurs Pract Today. 2020;7(2):80-3.

7. Kao H-Y, Ko H-Y, Guo P, Chen C-H, Chou S-M. Taiwan's experience in hospital preparedness and response for emerging infectious diseases. Health Secur. 2017;15(2):175-84. doi:10.1089/hs.2016.0105

8. Mortelmans LJ, Gaakeer MI, Dieltiens G, Anseeuw K, Sabbe MB. Are Dutch hospitals prepared for chemical, biological, or radionuclear incidents? A survey study. Prehosp Disaster Med. 2017;32(5):483-91. doi:10.1017/S1049023X17006513

9. Rao TS, Radhakrishnan R, Andrade C. Standard operating procedures for clinical practice. Indian J Psychiatry. 2011 Jan;53(1):1-3. doi:10.4103/0019-5545.75542.

10. De Pourcq K, De Regge M, Van den Heede K, Van de Voorde C, Paul G, Eeckloo K. The role of governance in different types of interhospital collaborations: a systematic review. Health Policy. 2019;123(5):472-9. doi:10.1016/j.healthpol.2019.02.010 
11. Heymann DL, Shindo NJTL. COVID-19: what is next for public health? Lancet. 2020;395(10224):542-5. doi:10.1016/So1406736(20)30374-3

12. Peiffer-Smadja N, Lucet J-C, Bendjelloul G, Bouadma L, Gerard S, Choquet C, et al. Challenges and issues about organizing a hospital to respond to the COVID-19 outbreak: experience from a French reference centre. Clin Microbiol Infect. 2020;26(6):669-72. doi:10.1016/j.cmi.2020.04.002

13. Comprehensive hospital preparedness checklist for coronavirus disease 2019 (COVID-19). Atlanta, Georgia: Centers for Disease Control and Prevention; 2020.

14. Hospital readiness checklist for COVID-19. Interim document, version 5. 2020. Washington DC: Pan American Health Orgnization; 2020 (PAHO/PHE/CPI/COVID-19-20-0024; https://iris.paho.org/handle/10665.2/52402, accessed 19 November 2020).

15. Coronavirus disease 2019 (COVID-19). Hospital preparedness assessment tool. Atlanta: Centres for Disase Control and Prevention; 2020 (https://www.mass.gov/doc/cdc-hospital-preparedness-checklist/download, accessed 23 November 2020).

16. Checklist for hospitals preparing for the reception and care of coronavirus 2019 (COVID-19) patients. ECDC Technical Report. Stockholm: European Centre for Disease Prevention and Control; 2020.

17. Olivieri C, Ingrassia PL, Della Corte F, Carenzo L, Sapori J-M, Gabilly L, et al. Hospital preparedness and response in CBRN emergencies: TIER assessment tool. Euro J Emergency Med. 2017;24(5):366-70. doi:10.1097/MEJ.0000000000000399.

18. Hopkins RS, Misegades L, Ransom J, Lipson L, Brink EW. SARS preparedness checklist for state and local health officials. Emerg Infect Dis. 2004 Feb;10(2):369-72. doi:10.3201/eid1002.030729.

19. Adini B, Verbeek L, Trapp S, Schilling S, Sasse J, Pientka K, et al. Continued vigilance-development of an online evaluation tool for assessing preparedness of medical facilities for biological events. Front Public Health. 2014;2:35. doi:10.3 389/fpubh.2014.00035. 